\title{
Quem lê livros espíritas?
}

\author{
Who reads spiritualist books? \\ ¿Quién lee libros espiritistas? \\ Ana Claudia da Silva* \\ Verônica Bemvenuto de Abreu e Silva ${ }^{*}$
}

\section{Resumo}

O crescimento do mercado editorial espírita permite aventar a hipótese de formação de um leitor particular, que busca na literatura espírita conhecimento e consolação. A partir de nossa experiência como leitoras, buscamos identificar o perfil do leitor brasileiro de livros espíritas, obtido mediante coleta de dados em todo o território nacional. A investigação tem por base a pesquisa "Retratos da Leitura no Brasil" e procura colher, entre leitores majoritariamente espíritas, informações que os identifiquem como cidadãos brasileiros e que traduzam suas experiências de leitura, tais como autores que mais admiram, leituras em andamento, obras marcantes, hábitos e práticas de leitura.

Palavras-chave: literatura espírita, mercado editorial espírita, práticas de leitura.

\section{Abstract}

The growing Spiritualist editorial market suggests a need to establish the particular kind of reader who seeks knowledge and consolation in Spiritualist literature. Based on our experience as readers, we seek to identify the profile of the Brazilian reader of Spiritualist books, obtained through the collection of data across the country. Our research is based on the study "Retratos da Leitura no Brasil" and seeks to collect, among readers who are mostly Spiritistualist, information that identifies them as Brazilian citizens and that translates their reading experiences, such as authors they admire, readings in progress, reading habits and reading practices.

Keywords: spiritist literature, spiritist editorial market, reading practices.

\section{Resumen}

El crecimiento del mercado editorial espiritista permite sugerir la hipótesis de la formación de un lector particular, que busca en la literatura espiritista conocimiento y consuelo. Desde nuestra experiencia como lectores, tratamos de identificar el perfil del lector brasilero de libros espiritistas, obtenido por la recopilación de datos en todo el territorio nacional. Nuestra investigación se basa en la encuesta "Retratos de lectura en Brasil" y trata de observar, entre los lectores mayormente espiritistas, información que los identifiquen como ciudadanos brasileros y que reflejen sus experiencias de lectura, tales como los autores que más admira, sus lecturas en curso, obras notables, los hábitos y las prácticas de la lectura.

Palabras clave: literatura espiritista, mercado editorial espiritista, prácticas de lectura.

\section{Eu, Ana}

Sou professora da Universidade de Brasília e moro em São Sebastião. Quem conhece a Capital sabe que esse bairro é um dos muitos espaços marginais que circundam Brasília; em contraponto, a UnB se situa no espaço superior - dizemos, efetivamente: "vamos subir ao Plano Piloto" -, não só geograficamente. O Plano representa o que há de melhor em Brasília em termos econômicos; lá

\footnotetext{
* Doutora em Estudos Literários e professora da Universidade de Brasília (UnB), Brasília, DF, Brasil. iDorcid.org/0000-0003-3948-8931. E-mail: aclaudasilva@gmail.com.

** Mestranda em Literatura na Universidade de Brasília (UnB), Brasília, DF, Brasil. (Dorcid.org/0000-0003-1297-258X. E-mail: veronicareginadeabreu@hotmail.com.
} 
as ruas são todas asfaltadas e não precisamos, por exemplo, fechar a janela do carro para evitar os golpes de poeira que diariamente açoitam os moradores de São Sebastião.

Entre os fatos relevantes para esta pesquisa que formam minha identidade, cumpre também explicitar que sou esposa do Chico, cuja vida tem sido dedicada ao teatro brasileiro pelo menos nos últimos 25 anos. Chico possui a sabedoria dos palcos, diferentemente da minha sabedoria livresca - que sempre onera nossas mudanças de casa e ou de cidade! Foi na convivência com ele que comecei a ler romances espíritas, para alcançar e abraçar, por curiosidade (e, depois, por amor), sua visão de mundo, conformada pela educação espírita livresca que ele até então possuía.

Mil quilômetros nos separaram dos amigos e familiares paulistanos quando mudamos para Brasília no final de 2012, dotando-nos, assim, da feliz solidão que nos impulsionou a buscar a companhia na circunvizinhança de pessoas com as quais tivéssemos alguma afinidade. Foi assim que chegamos, no final do ano seguinte, ao Centro Espírita Renovação e Fraternidade (CERF), onde fomos recebidos com o abraço de que tanto carecíamos. Ali começamos, em 2014, o Estudo Sistemático da Doutrina Espírita (ESDE). Fui alocada na turma de iniciantes e meu marido, na turma do segundo ano.

Esse fato foi relevante para o início do meu interesse pela literatura espírita. Não só porque a leitura de romances espíritas, especialmente os canônicos, seja recomendada pelos instrutores como fonte de conhecimento sobre a $\mathrm{DE}$, mas principalmente porque minha turma era composta, em sua maioria, por mulheres trabalhadoras a quem a necessidade de ganhar a vida tirou cedo da escola. Percebi isso pela forma como minhas novas amigas faziam suas leituras em voz alta: os tropeços e descontinuidades evidenciavam falta de familiaridade com termos medianamente eruditos e pouca afinidade com as práticas escolares de leitura, entre as quais a leitura oral ocupa lugar de destaque. ${ }^{1}$

Não apenas minha função como professora me destacou nesse grupo, mas também o desenvolvimento do Projeto Ler no Lar que, desde 2015, incentiva junto às famílias atendidas pelo serviço social do CERF a leitura de livros espíritas. A composição do acervo circulante desse projeto me responsabilizou pela compra de mais de 300 livros espíritas para não adultos, levando a Presidência do CERF a me registrar junto às livrarias e editoras especializadas como pessoa responsável pela aquisição de livros com desconto institucional significativo (em torno de 30\%). Sabedoras dessa minha condição especial de compradora, minhas amigas de curso adquiriram o hábito de solicitar a inclusão nas listas de compras de determinados títulos cuja leitura lhes interessava. Tratava-se basicamente de romances espíritas, que, por meu intermédio, essas mulheres compravam para suas bibliotecas particulares. Ali estava eu, então, mediando a compra de livros para pessoas que a minha ignorância acadêmica me faria talvez classificar como não leitoras.

Já surpresa com tais pedidos de aquisição de livros, passei a observar também que essas leituras conferiam a elas um saber que se somava àquilo que nos era apresentado no curso: essas improváveis leitoras não raro ilustram as aulas, até hoje, com episódios retirados das páginas de romances espíritas, cuja leitura somou a ficção à bagagem de vida, transformando-a em experiência própria, verdadeira, real. Esses fatos semearam, então, o chão sobre o qual eu viria a me debruçar, nos anos seguintes, em minhas pesquisas acadêmicas: a literatura espírita e seus leitores.

\section{Eu, Verônica}

O papel da arte - e consequentemente da literatura -, para mim, sempre foi o de emocionar. Se a obra não comove, ela não cumpre seu papel. Há algo nos romances mediúnicos que mexe comigo enquanto leitora, principalmente nos momentos difíceis pelos quais passei. A proposta do espiritismo é consolar, e encontrei conforto em sua literatura sempre que a procurei.

\footnotetext{
${ }^{1} \mathrm{O}$ estudo sobre a prática da leitura oral nas escolas foi tema de minha primeira iniciação científica, realizada na Universidade de São Paulo no âmbito do megaprojeto "A circulação de textos na escola", coordenado por Lígia Chiappini, sob a orientação de Maria Helena Hatsue Nagamine Brandão (Silva e Carbonari, 1997).
} 
Nasci no que chamamos de lar espírita. Minha família materna já era atuante em casas espíritas do Distrito Federal há bastante tempo e foi nesse meio que cresci e me desenvolvi. Desde minha infância, participava das aulas de evangelização espírita, nas quais me foram apresentados o espiritismo e suas obras; foi esse o primeiro contato que tive com a literatura espírita.

Sou formada em Museologia e já no curso de graduação dirigi minhas pesquisas ao estudo entre arte, religião e representação. Esse sempre foi um assunto de interesse e frequentemente discutido na Ciência da Informação. Ao me preparar para continuar os estudos na pós-graduação, conheci a professora Ana Claudia, que estava iniciando estudos acerca da literatura espírita. Foi então que resolvi juntar algo que faz parte de minha identidade (espiritismo) a um campo com o qual sempre tive afinidade, mas em que nunca tivera a oportunidade de me aprofundar.

Ao iniciar pesquisas acerca do assunto e em conversas com colegas e amigos, tanto do meio espírita quanto do meio acadêmico, surgiu a necessidade de averiguar quem é o público leitor de livros espíritas e por quê lê essas obras. Sempre tive comigo, talvez por estar nesse meio, que os romances mediúnicos, principalmente, sempre foram bastante lidos, até mesmo por pessoas que não são espíritas. Essa pesquisa veio confirmar algumas suspeitas e surpreender em outros aspectos, além de dar aporte para futuros estudos.

\section{Literatura espírita e mercado}

As experiências acima relatadas constituem o ponto de partida da formação de muitos leitores da literatura espírita: ou nascemos numa família espírita, ou chegamos até essa literatura por influência de amigos. O estudo da literatura espírita que realizamos na UnB no âmbito do Grupo de Pesquisa Literatura e Espiritualidade fundamenta-se no que Nakagome chamou de "respeito ao leitor", na "necessidade de reconhecer que o outro pode ter uma relação com a leitura que é, por circunstâncias diversas, muito diferente da minha experiência específica com o texto, pautada num caminho de formação acadêmica" (Nakagome, 2017, p. 136). De fato, nada parece mais avesso à academia que o estudo das produções literárias espíritas, mormente aquelas que são compostas pelo mecanismo da psicografia. Obriga-nos o ceticismo acadêmico a questionar o valor literário dessas obras, principalmente devido a seu apelo popular. Marquet (2008, p. 1, tradução nossa) elenca os elementos comuns da chamada "literatura popular": "simplista, maniqueísta; nela destaca-se uma lógica que finge ser infantil, é cheia de convenções banais, despojada de uma intenção estilística definida e não tem outra intenção além de ser inovadora". Bem distante dessa descrição vão os romances espíritas, que revelam estruturas bem amarradas; personagens redondas que evoluem e se transformam ao longo da narrativa, em cujas consciências o bem e o mal encenam avanços e recuos morais; enredos complexos cujo clímax revela-se epifânico; espaços dilatados pela imaginação de mundos extraterrenos e tempos que se pautam pela perspectiva da imortalidade do espírito. O que, então, nos leva a pensar que essa literatura tenha apelo popular, se a sua estrutura não é menos complexa que a dos romances tradicionais do cânone literário?

O aspecto mais inovador da literatura espírita coincide com o que há de novo na própria DE, considerada como a terceira revelação de Deus aos homens, ${ }^{2}$ trazendo ensinamentos sobre a vida além-túmulo, a qual expande os limites possíveis das narrativas de matriz doutrinária. A perspectiva espírita chancela no romance a comunicação entre vivos e mortos (nomeados respectivamente como encarnados e desencarnados), a vida em outros orbes, a reencarnação orientada pelas leis do progresso moral e intelectual da alma, ${ }^{3}$ que segue por inúmeras existências em evolução contínua. ${ }^{4} \mathrm{~A}$ temática da literatura espírita constitui, assim, seu maior atrativo.

\footnotetext{
${ }^{2}$ Segundo a DE, a primeira revelação de Deus aos homens foi feita mediunicamente por Moisés, que recebeu de Deus os dez mandamentos que dirigiram a conduta do povo hebreu; a segunda, por Jesus Cristo, que ampliou os limites da primeira, trazendo a lição do amor como caminho existencial para toda a humanidade; a terceira, por fim, consiste nas revelações dos Espíritos codificadas por Kardec, resumidas em seus cinco princípios: existência de Deus, imortalidade da alma, pluralidade das existências, pluralidade dos mundos habitados e comunicabilidade dos espíritos.

${ }^{3} \mathrm{O}$ espiritismo designa como alma o espírito enquanto encarnado.

${ }^{4}$ A DE é contemporânea do positivismo e dos estudos de Darwin, publicados na mesma época: A origem das espécies (Darwin, 2017) foi publicada em 1859, dois anos depois de O livro dos espíritos (Kardec, 2000). Souza (2013) destaca que ambas as obras foram de
} 
Por sua vez, o mercado editorial espírita vem crescendo ao longo dos anos, consolidando-se na década de 1990, quando "a ideia do produto barato e de apresentação simples já não mais se sustentava frente às novas realidades" (Garcia, 2015, s.p.), como na "era romântica" de divulgação de livros editados principalmente pelas editoras das federações espíritas estaduais e pela nacional, a FEB. A profissionalização desse ramo editorial trouxe certo embaraço aos empresários e ao público leitor:

Ações agressivas de marketing num mercado acostumado a uma espécie de caridade e desprendimento geram reações de desconforto; campanhas publicitárias planejadas segundo os princípios da persuasão e da sedução ocasionam constrangimentos, mas vão convencendo um público acostumado às mensagens pagas de uma cultura de consumo na qual foram educados (Garcia, 2015, s.p.).

As editoras espíritas passaram a investir na qualidade do livro e em projetos gráficos atraentes, trazendo a seu público a satisfação da leitura unida ao prazer tátil proporcionado pelos novos objetos. O surgimento de distribuidoras especializadas também favoreceu o crescimento desse mercado e as parcerias com redes de livrarias on-line ampliaram o seu acesso.

A literatura espírita, que tem no romance seu objeto mais procurado, ao lado de biografias, contos, crônicas, livros para não adultos (Adria, 2016), tem no âmbito dos seguidores da DE um público bastante fiel, para o qual são produzidas sempre novas obras. Stoll afirma:

Num momento em que a inserção na mídia, em especial a televisão, se destaca como fator de divulgação doutrinária, constituindo um novo campo de disputa no espaço público, o Espiritismo vem alargando sua inserção social, especialmente entre os segmentos da classe média, por meio do investimento no campo literário (Stoll, 2004, p. 181).

O surgimento de novas editoras espíritas no final do século XX é um dos sinais do crescimento nesse setor. Para Lewgoy (2000), o espiritismo é uma religião do letramento, da leitura e do livro. Também Cavalcanti (1983, p. 12) o afirma: “O Espiritismo é uma religião letrada, codificada. O livro, a leitura, o estudo, ocupam um lugar importante [...] em seu sistema ritual". Por isso, os livros espíritas possuem mercado editorial e público em expansão. Lewgoy explicita que a particularidade do espiritismo não seria apenas ser uma "religião do livro", mas uma religião cujo principal meio de divulgação, aprendizado e atualização é pela leitura: "O espiritismo é uma das modalidades religiosas que mais enfatiza a relação com a leitura sistemática e a exegese de fatos da vida em termos de conhecimentos adquiridos através da incorporação de sua doutrina pelo estudo" (Lewgoy, 2000, p. 113). Nas instituições espíritas, o estudo é uma ferramenta sem a qual não se processam o desenvolvimento moral e intelectual necessários ao progresso espiritual do crente. Os centros espíritas são procurados, comumente, por pessoas em estado de sofrimento, especialmente aquele provocado pela morte de entes queridos. A pessoa carente é levada a participar das sessões mediúnicas onde há distribuição de passe e água magneticamente fluidificada, elementos confortadores; é instada, também, a participar das palestras, que são momentos privilegiados de divulgação de conhecimentos básicos da $\mathrm{DE}$ ou do evangelho cristão lido à luz da mesma doutrina. $\mathrm{O}$ paciente é convidado também a participar de estudos sistemáticos da doutrina, organizados em cursos ministrados em toda casa espírita. O estudo é, assim, uma ferramenta indispensável para essa prática doutrinária.

Entre as obras indicadas aos espíritas para estudo encontramos, primeiramente, as chamadas Obras Básicas da Codificação Espírita, que reúnem cinco obras organizadas por Allan Kardec. Cavalcanti explica:

A codificação é um conjunto de cinco obras: o Livro dos Espíritos, que aparece pela primeira vez em 1857, e contém "o núcleo e arcabouço geral da doutrina"; o Livoro dos Médiuns, continuação do primeiro e que "pesquisa o processo das relações mediúnicas, estabelecendo as leis e

difícil aceitação em sua época; a despeito de contrastarem uma visão materialista e outra espiritualista, essas duas obras se aproximam; seu conteúdo "foi capaz de não somente abalar toda a estrutura da mentalidade humana, mas, também, de mudar a compreensão do ser humano sobre si próprio e de seu lugar no universo." (Souza, 2013, pos. 358). A evolução dos espíritos, que Kardec descobriu por revelação dos espíritos, segue paralela à teoria da evolução material das espécies, elaborada cientificamente por Darwin. 
condições do intercâmbio espiritual"; o Evangelho segundo o espiritismo, que explicita o conteúdo moral [...]; O Céu e o Inferno, que discute "as penas e gozos terrenos e futuros"; A Gênese, os Milagres e as Predições, que "trata dos problemas genésicos e da evolução física da terra" (Cavalcanti, 1983, p. 14).

Tais obras são fundamentais por três razões: unificam o pensamento espírita, dando-lhe identidade; constituem-se em fonte de autoridade diante de eventuais dissensões na interpretação da doutrina; por fim, nas reuniões espíritas sua leitura ocupa papel de destaque (Cavalcanti, 1983).

Em seguida à leitura das obras básicas, são indicadas obras de caráter literário, que atuam como fontes complementares de informações sobre o espiritismo; apesar do caráter ficcional, tais obras, produzidas muitas vezes pelo processo da psicografia mediúnica, são tratadas como relatos verídicos sobre a vida no chamado Mundo Maior. É comum que passagens de seus textos sejam citadas no estudo doutrinário, obliterando o mero caráter de representação literária, a qual é frequentemente tomada pelo objeto representado. ${ }^{5}$

Embora atraia também leitores não espíritas, essa literatura constitui uma parte importante do sistema de socialização e aprendizado dos espíritas. Juntamente com o exercício da caridade, a prática do estudo é fundamental para o processo de sociabilidade e apreensão de conhecimentos no espiritismo, fazendo com que a pessoa que não possui o hábito da leitura comece a desenvolvê-lo a partir da leitura de livros espíritas.

A indissolubilidade entre práxis espírita e leitura ensejou o surgimento de um segmento editorial específico e bastante desenvolvido. Em 2002, esse segmento vendeu 7 milhões de livros (Mansur e Cordeiro, 2003); em 2012, a estimativa do rendimento do mercado editorial espírita era de aproximadamente $\mathrm{R} \$ 500$ milhões ao ano (Espiritismo..., 2012). Com o adensamento do mercado consolida-se também um público leitor específico, com características próprias, formando o corpo de consumidores mais ou menos críticos dessa literatura. Nossa pesquisa tem o objetivo de traçar, de maneira inicial, o perfil do leitor de livros espíritas no Brasil.

\section{Metodologia}

Reunimos nesta pesquisa a metodologia qualitativa, mediante pesquisa bibliográfica, e quantitativa, com o uso de questionários. Tomamos por base os estudos produzidos no âmbito da pesquisa "Retratos da leitura no Brasil", cujos resultados e instrumentos de coleta serviram de base para a formação de nosso questionário de pesquisa.

Inicialmente elaboramos uma versão de teste do instrumento de coleta de dados, e a submetemos a um grupo de dezesseis profissionais de diferentes categorias: professores universitários, escritores, livreiros, palestrantes e educadores, todos ligados ao universo do livro espírita. Suas respostas nos ajudaram a promover ajustes no instrumento de coleta de dados, principalmente no que dizia respeito à pergunta sobre a identificação de gênero do entrevistado, a cuja versão final chegamos após termos consultado pesquisadores da área. Optamos por manter a forma de pergunta com resposta aberta, tal como nos foi indicado por pessoas transgêneras. ${ }^{6}$

O questionário foi submetido por cinco dias à comunidade espírita brasileira por meio de convite enviado pelo aplicativo de mensagens WhatsApp, alcançando a marca inesperada de 15.619 respostas, a qual nos fez encerrar a pesquisa antes do planejado, devido ao congestionamento da plataforma utilizada, o Google Forms. As perguntas foram divididas em dois grupos: questões de identificação e questões de hábitos e preferências do leitor. No primeiro grupo indagamos sobre o estado, a cidade, a raça, o gênero, a religião, o nível de

\footnotetext{
${ }^{5}$ Entre essas obras, duas séries ocupam lugar de destaque: a coleção “A Vida no Mundo Espiritual” ou "Série André Luiz", com 13 romances que narram as experiências do narrador autodiegético no mundo além-túmulo, e a série "Romances de Emmanuel", com cinco romances históricos, quatro dos quais remontam aos primeiros séculos do cristianismo e narram diferentes reencarnações do autor; o quinto mantém a temática, deslocando a ação narrativa para o século XVII. Outros romances, como Brasil, coração do mundo, pátria do Evangelho (Campos, 2015), também são incluídos entre as obras literárias que fornecem conhecimento doutrinário de alto valor para os espíritas.

${ }^{6}$ Já nos questionários de testagem da pesquisa percebemos que a indagação sobre a identidade de gênero causou estranhamento em alguns sujeitos, reforçando o caráter conservador de parte desse público.
} 
escolaridade e a renda familiar do leitor; indagamos, ainda, se o sujeito se considerava um leitor. Para os que responderam negativamente, a pesquisa encerrou-se ali. Também perguntamos, aos que se consideravam leitores, se liam livros espíritas. Caso esta última resposta fosse negativa, o sujeito seria igualmente encaminhado para a página de agradecimentos; por sua vez, a resposta positiva o levava à continuidade da pesquisa.

No segundo grupo, reunimos questões sobre formas de acesso aos livros, suporte preferido, gêneros literários lidos recentemente (no último ano), motivação da leitura, local preferencial de leitura, frequência e dificuldades da leitura, influências determinantes, quantidade de livros lidos no último trimestre, destinação do livro após a leitura, leitura em curso, livros e autores marcantes e aspectos do livro determinantes para a leitura. Nesta segunda parte obtivemos 15.328 respostas, pois 291 pessoas alcançadas pela pesquisa não se consideravam leitores de livros espíritas.

Nosso objetivo inicial foi conhecer o perfil do leitor espírita, mas nosso instrumento de coleta de dados nos permitiu conhecer apenas o perfil do leitor de livros espíritas, visto que alguns dos respondentes $(1,9 \%)$ leem livros espíritas, mas não se consideram adeptos do espiritismo.

Curiosamente, a autoidentificação como leitor $(93 \%)$ é menor que o número dos que afirmam ler livros espíritas $(98,1 \%$ ), ou seja, 5,1\% dos sujeitos que leem livros espíritas não se consideram leitores. Isso nos faz questionar qual seria o conceito de leitor internalizado por esses respondentes. Ao que tudo indica, para eles o leitor não é apenas aquele que lê, mas o que o faz em alguma circunstância particular. Sabemos que há diferentes graus de aproveitamento que vão desde a leitura por entretenimento até a leitura crítica, mas esta informação é reservada aos pesquisadores da leitura, àqueles que se interessam pelo exercício da leitura. Nossa hipótese é que para esses 5,1\% de sujeitos que leem, ser leitor implica em ler frequentemente, e não ocasionalmente. Consideram leitores, possivelmente, apenas aqueles que têm o hábito da leitura. De qualquer modo, é significativo que o conceito de leitor implique em algo mais que apenas na descodificação de caracteres alfabéticos; podemos afirmar com segurança que 5,1\% dos sujeitos refletem sobre a prática da leitura.

\section{Identidade do leitor de livros espíritas brasileiro}

Na primeira sessão do questionário identificamos que, apesar de termos recebido respostas de todos os estados do país, a maioria das pessoas que responderam às perguntas são provenientes da região Sudeste, dos estados do Rio de Janeiro, de São Paulo e de Minas Gerais. Essa constatação coincide em parte com os dados do censo demográfico realizado em 2010 pelo Instituto Brasileiro de Geografia e Estatística (IBGE), cuja análise apontava o Rio de Janeiro como estado com o maior número de espíritas (4\%), seguido do Distrito Federal (3,5\%), de São Paulo (3,3\%) e do Rio Grande do Sul (3,2\%) (Franzolim, 2012).

Descobrimos também que o perfil do leitor de livros espíritas é de um público não jovem; a maioria dos respondentes está na faixa etária de 51 a 60 anos, seguida pela dos leitores entre 41 a 50 anos de idade. Como essa literatura responde a inquietações sobre a morte, a comunicação com espíritos desencarnados e a vida além-túmulo, pareceu-nos natural que seu leitor se situasse majoritariamente nas faixas etárias finais da vida corpórea.

A questão sobre a identidade de gênero com a qual o sujeito se identificava causou bastante confusão entre os respondentes. Conforme se observa na tabela 1 , a maioria dos sujeitos se declarou como sendo do gênero feminino $(64,7 \%)$ e somente $23,3 \%$ declararam identidade masculina. Notamos também uma grande confusão com relação à orientação sexual: $3,5 \%$ dos sujeitos indicaram a sua orientação sexual (heterossexual, por exemplo), em vez do gênero com que se identificavam. Outros $8,4 \%$ deram respostas que não se classificavam em nenhum dos agrupamentos anteriores; algumas delas, por se tratar de pesquisa literária, indicaram os gêneros literários de sua predileção. 
Tabela 1 - Identidade de gênero

\begin{tabular}{l|c}
\hline \multicolumn{1}{c}{ Opções de resposta } & Respostas (\%) \\
\hline Feminino & 64,7 \\
Masculino & 23,3 \\
Resposta diversa & 8,4 \\
Orientação sexual & 3,5 \\
\hline
\end{tabular}

Fonte: dados da pesquisa.

Chamou-nos a atenção, nesse quesito, as críticas recebidas direta e indiretamente ao tipo de questão formulada. Pareceu-nos que a discussão sobre gênero que perpassa a sociedade contemporânea é tida por inócua na opinião de alguns espíritas; registramos inclusive traços da reação (violenta) de apagamento do problema de gênero, como observamos na seguinte resposta: ${ }^{7}$ "Não acredito que uma pesquisa espírita faça esse tipo de pergunta. Me recuso a responder isso. Vou formular a pergunta de forma correta. Qual o seu sexo? Feminino." Primeiro a respondente apresenta a inadequação da questão na ótica espírita, depois declara sua recusa a responder (rejeição à abordagem do tema) e, em seguida, apresenta a correção da nossa questão, silenciando o problema de gênero e sugerindo, em seu lugar, a identidade biológica: o sexo. ${ }^{8}$

Outro grupo de respostas discrepantes foi o dos que desqualificaram a pergunta, apresentando como resposta pontos de interrogação, ou simplesmente declarando não ter entendido a pergunta ou, ainda, qualificando-a como estranha. Há ainda aqueles que confundem conceitos como gênero, sexo ("gênero só existem dois") e raça ("Gênero humano. Sexo é algo diferente.").

Outros, ainda, apresentaram sentimentos ligados à questão do gênero, dizendo apenas que gostam do próprio gênero, são bem resolvidos, sentem-se confortáveis, felizes ou confusos. Talvez porque o ambiente acadêmico contemporâneo nos condicione a vigiar nossas atitudes com relações às questões de gênero, algumas destas respostas soaram-nos com uma ponta de cinismo, mas não temos como distinguir efetivamente, nas respostas escritas, ironia de ignorância - o que se aplica, ainda, ao grupo dos que desqualificaram a questão. Podemos captar, contudo, a necessidade de abordar essa questão com mais clareza no âmbito do movimento espírita. ${ }^{9}$

Quanto à raça (tabela 2), a grande maioria dos respondentes (63,3\%) se declarou como branca. Em seguida vêm os grupos dos autodeclarados pardos $(27,1 \%)$ e negros $(7,2 \%)$.

Tabela 2 - Raça

\begin{tabular}{l|c}
\hline \multicolumn{1}{c}{ Opções de resposta } & Respostas (\%) \\
\hline Branca & 63,3 \\
Parda & 27,1 \\
Negra & 7,2 \\
Asiática & 0,6 \\
Indígena & 0,3 \\
Mestiça & 0,1 \\
Não quis identificar/Não concorda com a questão & 1,1 \\
Outros & 0,3 \\
\hline
\end{tabular}

Fonte: dados da pesquisa.

\footnotetext{
${ }^{7}$ Os sujeitos da pesquisa não foram identificados; reproduzimos, assim, apenas a sua voz.

${ }^{8}$ Outros respondentes também recusaram a questão de gênero, afirmando: "Gênero não, SEXO masculino!"; "Não tenho gênero. Tenho sexo: masculino." O uso de negativas e das letras maiúsculas traduzem a inquietação com a pergunta e o autoritarismo do sujeito.

${ }^{9}$ Os palestrantes ocupam lugar privilegiado na formação dos adeptos da Doutrina dos Espíritos. Nomes de destaque como Haroldo Dutra Dias já abordaram o tema sob a ótica espírita, registrando a importância da educação para a diversidade e da aceitação amorosa da pessoa diferente (Dias, 2018). O grupo teatral Amigos da Luz, que produz vídeos de humor espírita, também problematizou o tema (Pode ser gay?, 2017).
} 
A maior incidência entre as respostas discrepantes foi a dos que se identificam como miscigenados ou misturados; houve também alusão ao mito das três raças, segundo o qual o brasileiro é a mistura de europeus, isto é, portugueses; africanos ou, melhor dizendo, escravizados, e indígenas, a quem tudo foi subtraído. A ideia criativa ${ }^{10} \mathrm{e}$ incorreta, do ponto de vista doutrinário, de que somos frutos da miscigenação de espíritos também foi documentada.

Assim como vimos acontecer com o conceito de gênero, também o de raça foi desqualificado por alguns respondentes. Alguns negaram decididamente a problematização racial, afirmando que "isso não importa" ou que essa discriminação "não é necessária". Outra forma de desqualificar o discurso racial - ou, melhor dizendo, a histórica luta pelos direitos dos afrodescendentes - é negar a sua existência, escamoteando a questão sob a alegação de que o conceito de raça é cientificamente inoperável: "não tenho (ou não me identifico com) raça", "não considero ético classificar as pessoas por raça". Causou-nos espécie ainda a incidência dessa alegação, revelando um distanciamento de parte da comunidade espírita das questões raciais que mobilizam o Brasil na contemporaneidade. Percebeu-se inclusive o sarcasmo de respostas como "infelizmente não tenho pedigree". Esquecidos de sua condição de alma, ou seja, de espírito encarnado, ${ }^{11}$ houve ainda quem alegasse que o espírito não tem raça, mas é universal.

Todas essas respostas procuram, conscientemente ou não, esvaziar a luta contra o racismo, protagonizada pelos movimentos negros brasileiros, que têm conquistado nos últimos anos algumas vitórias consubstanciadas nas chamadas ações afirmativas. A problemática do racismo, porém, está longe de ser assumida, o que observamos por algumas reflexões que nos foram apresentadas, tais como: "Tenho pele clara e cabelo fino, no entanto sou filha de uma mulher branca com um homem negro", que descreve a contradição entre o fenótipo branco e o genótipo interracial; ou, ainda, a respondente que afirma: "Tenho a pele branca mas sou neta de negros. Como você identificaria minha raça!?" - embora reconheça a ascendência negra, delega para o outro a solução, fugindo do enfrentamento da própria condição racial. Identificações como raça humana ou homo sapiens também foram apresentadas; embora sejam biologicamente corretas, também esse discurso é uma linha de fuga para o racismo. Kabengele Munanga esclarece:

Podemos observar que o conceito de raça tal como o empregamos hoje, nada tem de biológico. É um conceito carregado de ideologia, pois [...] esconde uma coisa não proclamada: a relação de poder e de dominação. A raça, sempre apresentada como categoria biológica, isto é, natural, é de fato uma categoria etnossemântica. De outro modo, o campo semântico do conceito de raça é determinado pela estrutura global da sociedade e pelas relações de poder que a governam (Munanga, 2014, p. 6).

A confusão conceitual - que o texto supracitado de Munanga esclarece - entre raça e etnia também foi assinalada por um dos sujeitos que sugeriu que a pergunta deveria ter mencionado etnia e não raça. Este fator, juntamente com aqueles anteriormente mencionados, também aponta para a necessidade de atualização do discurso doutrinário. É sabido que Allan Kardec, o codificador (organizador) da Doutrina dos Espíritos, é acusado de racismo por algumas declarações em que ficava evidente a condição inferior do homem negro, tal como esta:

Assim, como organização física, os negros serão sempre os mesmos; como Espíritos, trata-se, sem dúvida, de uma raça inferior, isto é, primitiva; são verdadeiras crianças às quais muito pouco se pode ensinar. Mas, por meio de cuidados inteligentes é sempre possível modificar certos hábitos, certas tendências, o que já constitui um progresso que levarão para outra existência e que lhes permitirá, mais tarde, tomar um envoltório em melhores condições. Trabalhando em sua melhoria, trabalha-se menos pelo seu presente que pelo seu futuro e, por pouco que se ganhe, para eles é sempre uma aquisição (Kardec, 2004, p. 150-151).

\footnotetext{
${ }^{10}$ No quesito respostas criativas, outras nos chamaram a atenção, como as de sujeitos que se autodefiniram como "bege", "encarnado na Terra", "filha de Deus". Não sabemos, também neste caso, o limite entre ironia e ignorância. O conceito de raça também foi confundido com nacionalidade; encontramos algumas alusões à "raça brasileira".

11 O espiritismo chama de alma à pessoa encarnada, ou seja, ao espírito enquanto vive transitoriamente a experiência da reencarnação, da vida no corpo físico terrestre.
} 
Trata-se de um pensamento flagrantemente racista, tal como o era a sociedade escravagista do século XIX, de cujo progresso científico Kardec também se apropriou. À época, eram bem vistos pelos cientistas os estudos da frenologia, especialidade que pretendia ler o caráter e a personalidade humanos, especialmente dos criminosos, pelo exame das saliências e reentrâncias da cabeça, associadas a tal ou qual função cerebral. Embora tenha dado ensejo a perigosos comportamentos tais como a eugenia ("purificação" das raças), essa teoria foi logo desacreditada, pois não conseguiu provar a relação entre a dimensão e a forma da cabeça e os padrões de comportamento humano. Hoje sabemos que esse estudo não passou de mais uma forma pseudocientífica para a justificação de práticas racistas. Kardec, embora acuse a distinção entre a frenologia - de base materialista - e o espiritismo, de base espiritualista, ainda expressa o preconceito racial inerente à sua época.

Ainda que pontuado em uma ou outra obra, tal racismo kardequiano deve ser, contudo, superado não só pelo avanço científico de hoje, mas ainda pelos resultados da luta contra o racismo. Em O livro dos espíritos (1984), Kardec insere (e, assim, subscreve) a lição de Erasto: "Mais vale rejeitar dez verdades do que admitir uma única mentira, uma única teoria falsa" (Erasto apud Kardec, 1984, p. 264). A lição sobre a inferioridade "natural" da raça negra deve ser, pois, contornada; de fato, não encontramos essa falsa assertiva reproduzida na proposta de estudo sistematizado da Doutrina. Assim, entendemos que a presença de estratégias do discurso racista na fala de alguns entrevistados se deve tanto ao racismo arraigado em nossa sociedade, quanto ao desconhecimento dos preceitos da própria DE.

No item religião, a maioria dos sujeitos afirmou ser espírita (92,7\%), mas houve pessoas de outras religiões (cerca de 6\%) que também participaram da pesquisa, principalmente católicos $(2,3 \%)$ e umbandistas $(1,8 \%) .^{12}$

Dois dados da pesquisa apontam o público leitor de livros espíritas como sendo altamente elitizado: são as questões que dizem respeito à escolaridade e à renda familiar das pessoas entrevistadas. Cerca de $81 \%$ da população entrevistada já concluiu ou está cursando o ensino superior; 31,1\% declararam ter uma renda familiar de 2,1 a 5 salários mínimos, $27 \%$ responderam que recebem entre 5,1 a 10 salários mínimos e $20,1 \%$ ganham mais de 10 salários mínimos. Somente $2,7 \%$ dos sujeitos afirmam ter uma renda familiar de até 1 salário mínimo. Lewgoy explica: "O espiritismo dos primeiros tempos já portava a marca polêmica e racionalista que caracteriza a sua origem europeia, mas, ao ser transplantado para o Brasil, ele penetra inicialmente em ambientes de uma elite letrada" (Lewgoy, 2000, p. 104). Embora nossa experiência pessoal diga o contrário, a leitura da literatura espírita ainda se encontra restrita à elite letrada e com acesso ao ensino superior.

\section{Hábitos e preferências do leitor de livros espíritas brasileiro}

A maioria das perguntas nessa sessão foi de múltipla escolha ou aberta, sendo que as pessoas podiam escolher várias respostas em uma mesma questão. Os resultados apresentados são frutos da preferência da maioria dos questionados. A questão sobre o modo de acesso ao livro espírita (tabela 3), de múltipla resposta, mostra que a maioria dos leitores $(90,9 \%)$ compra seus próprios livros, reforçando a ideia de que se trata de uma população de alto poder aquisitivo.

\footnotetext{
${ }^{12} \mathrm{O}$ questionário permitia também resposta aberta ao item religião. Os que optaram por ela mostraram que várias pessoas têm duas religiões - o par espírita/umbandista superando os demais em número de ocorrências. Outras pessoas declararam serem ecumênicas, sincréticas ou multirreligiosas. Chamou a atenção o número de ocorrências dos que, embora estudem a Doutrina dos Espíritos, não se consideram ainda espíritas - estes utilizaram verbos no gerúndio (tentando, estudando, migrando, adentrando etc.) para sinalizarem seu grau de pertencimento, ou declararam-se simpatizantes do espiritismo. Houve também um grupo de espíritas que declarou que espiritismo não é religião, mas filosofia de cunho moral. A pergunta pareceu atormentar especialmente alguns católicos, herdeiros da culpa original, que se viram na obrigação de sinalizar que foram batizados como católicos, embora não pratiquem a religião de seus pais ou pertençam a outra.
} 
Tabela 3 - Acesso ao livro espírita

\begin{tabular}{l|c}
\hline \multicolumn{2}{c}{ Como você tem acesso aos livros espíritas? } \\
\hline \multicolumn{1}{c}{ Opções de resposta } & Respostas (\%) \\
\hline Compro & 90,9 \\
Pego emprestado & 44,2 \\
Faço download & 35,3 \\
Ganho de presente & 33,6 \\
Fotocopio & 1,9 \\
\hline
\end{tabular}

Fonte: dados da pesquisa.

Notamos também nas respostas que a leitura de livros emprestados supera, nessa população, o download das obras, mesmo sendo muitas delas de distribuição gratuita e tratando-se de pessoas que certamente têm acesso às modernas tecnologias. Não obstante, indagada sobre o suporte preferido de leitura, a grande maioria delas (93,3\%) disse que prefere os livros impressos aos digitais, os quais são lidos majoritariamente (por 94,3\% dos sujeitos) em espaços fechados (casa, biblioteca, trabalho, casa de amigos ou parentes etc.); os que leem em locais abertos (transporte público, sala de aula, parques, praças, praia, clube, consultórios, salão de beleza ou barbearia etc.) são a minoria, confirmando o perfil economicamente privilegiado da população e indicando que a predominância de práticas intimistas na leitura do livro espírita. ${ }^{13}$

Quando indagada sobre a frequência de leitura, 29,65\% das pessoas afirmaram ter lido pelo menos um livro nos últimos três meses; $27,44 \%$ leram dois livros no mesmo período, seguidas pelo grupo das pessoas que leram três livros $(16,1 \%)$, quatro livros $(7,5 \%)$ e nenhum livro $(7,2 \%)$ no último trimestre. A maioria dos sujeitos $(31 \%)$, porém, afirmou que lê de três a quatro livros anualmente, seguida dos quase $21 \%$ da população entrevistada que lê de cinco a seis livros ao ano e dos 19,2\% que leem até dois livros por ano.

Com respostas de múltipla escolha, os sujeitos mostraram que os gêneros mais lidos no último ano, ou seja, 2017 foram as obras básicas da doutrina e obras de estudos, seguidas pelos romances (tabela 4).

Tabela 4 - Gêneros lidos em 2017

\begin{tabular}{l|c}
\hline \multicolumn{1}{c}{ Gêneros } & Respostas (\%) \\
\hline Obras básicas da Doutrina dos Espíritos & 82,1 \\
Estudos doutrinários & 76,9 \\
Romances & 48,2 \\
Contos & 11,9 \\
Livros infantis ou juvenis & 11,6 \\
Crônicas & 11 \\
\hline
\end{tabular}

Fonte: dados da pesquisa.

Entre as obras literárias lidas pelos sujeitos, o gênero romance supera os demais que, mesmos somados, não alcançariam o índice das leituras romanescas. Essa questão corrobora a pergunta seguinte, sobre a motivação da leitura de livros espíritas (tabela 5). A maioria das pessoas $(64,5 \%)$ afirma que lê para aprender, conhecer e estudar a Doutrina Espírita; outros estão em busca de reforma íntima, crescimento pessoal, consolo ou conforto.

\footnotetext{
${ }^{13}$ Embora a pesquisa não tenha sinalizado práticas de leitura coletiva, oral, do livro espírita, sabemos que elas existem. É comum que o dirigente das assembleias ou grupos de tratamento físico-espiritual ou de desobsessão abram as reuniões com a leitura de mensagens espíritas, veiculadas em livros não raramente literários.
} 
Tabela 5 - Motivação da leitura de livros espíritas

\begin{tabular}{l|c}
\hline \multicolumn{2}{c}{ Por que motivo você lê livros espíritas? } \\
\hline \multicolumn{2}{c}{ Opçães de resposta } \\
\hline Estudo, aprendizado, instrução e aquisição de conhecimento & Respostas (\%) \\
Gosto, prazer e lazer & 64,5 \\
Reforma íntima e busca de crescimento & 13,5 \\
Conforto ou consolo & 8,5 \\
Interesse & 4,4 \\
Autoidentificação & 2,3 \\
Por ser espírita & 1,9 \\
Curiosidade & 1,9 \\
Sensação de bem-estar & 0,6 \\
\hline
\end{tabular}

Fonte: dados da pesquisa.

Ao questionarmos o que impedia as pessoas, eventualmente, de ler mais livros espíritas (tabela 6), 58,2\% dos sujeitos afirmaram que o impedimento maior é a falta de tempo e $15,1 \%$ deles priorizam outras atividades, como trabalho, estudos, família etc. Outros 7,5\% dos respondentes declararam não haver nada que os impeça a ler mais esses livros.

Tabela 6 - Impedimentos para a leitura

\begin{tabular}{l|c}
\hline \multicolumn{1}{c}{ Opções de resposta } & Respostas (\%) \\
\hline Falta de tempo & 58,2 \\
Priorização de outras atividades (trabalho, família, estudos, compromissos, afazeres diversos etc.) & 15,1 \\
Nada & 7,5 \\
Falta de disciplina, hábito ou concentração & 4,8 \\
Preguiça ou desinteresse & 3,4 \\
Preço dos livros & 2,6 \\
Dificuldade de acesso aos livros & 1,4 \\
Predileção por outras leituras & 1,3 \\
Linguagem difícil & 0,5 \\
Predileção por TV e outras mídias & 0,2 \\
Outros impedimentos & 3,3 \\
\hline
\end{tabular}

Fonte: dados da pesquisa.

Sabemos que falta de tempo aponta para a priorização de outras atividades em detrimento da leitura, as quais, somadas com a predileção por TV ou outras mídias, formam $73 \%$ das alegadas dificuldades ou impedimentos para a leitura de livros espíritas. Apenas 1,3\% dos sujeitos afirma preferir outras leituras, em detrimento da espírita.

Nossa hipótese, ao indagar sobre a destinação dos livros após a leitura (tabela 7), foi de que, sendo o espiritismo uma doutrina que prega a caridade como meio de desenvolvimento espiritual, encontrássemos um número significativo de pessoas que não manteriam consigo os livros lidos, fazendo-os circularem pela comunidade. Aqui também as respostas múltiplas foram permitidas.

Exceto a primeira opção, as demais apontam todas para a possibilidade de circulação (gratuita ou não) do livro. Constatamos que o apelo à caridade, neste caso, não foi maior que o 
apego ao livro: a maioria dos sujeitos $(71,6 \%)$ retém os livros lidos, enquanto os que optam por formas de circulação do livro não chegam juntos a esse mesmo índice.

Tabela 7 - Destinação dos livros após a leitura

\begin{tabular}{l|c}
\hline \multicolumn{1}{c}{ O que fazem os leitores com os livros lidos } & Respostas (\%) \\
\hline Guardam & 71,3 \\
Doam & 38,6 \\
Presenteiam alguém & 16,7 \\
Emprestam & 6 \\
Devolvem & 0,5 \\
Vendem & 0,4 \\
Outros & 7,9 \\
\hline
\end{tabular}

Fonte: dados da pesquisa.

Inspiradas na pesquisa Retratos da leitura no Brasil (Amorim, 2008), resolvemos indagar ao nosso público quem são as pessoas que mais influenciam na escolha dos livros e com que frequência os entrevistados veem/viam pessoas da família lendo. A hipótese desta última questão é a de que crianças que crescem em famílias de leitores adquirem mais apreço pela leitura. Descobrimos, com a primeira questão, que os amigos são os maiores influenciadores na escolha dos livros (39,5\%), seguido de pais ou parentes (20,9\%). Os líderes religiosos ocupam o terceiro lugar desse ranking, com $17,9 \%$ das respostas, enquanto $14,2 \%$ dos sujeitos afirmam que não seguem senão a si mesmos na escolha dos livros espíritas que leem.

Com relação à exposição dos sujeitos a práticas familiares de leitura, 27,1\% declararam que tiveram sempre essa experiência; $29,7 \%$ afirmaram que presenciavam cenas de leitura de vez em quando, contra os $22 \%$ que raramente tiveram essa experiência e os $21,3 \%$ que afirmaram nunca terem visto pessoas da família lendo livros espíritas. A distribuição mais ou menos equivalente das respostas aponta para a pouca influência da leitura em família de livros espíritas para a formação dos atuais leitores, que são mais influenciados por amigos e líderes religiosos na seleção dos livros.

No tocante ao que mais os influencia na escolha de um livro, os sujeitos declararam que tema, dicas de outras pessoas, autor e título, nessa ordem, têm muito mais peso que resenhas, preço, capa ou editora. ${ }^{14}$

Foram feitas, finalmente, questões sobre os livros espíritas: leitura em andamento, obras marcantes e autores mais admirados. Todas as perguntas foram de resposta aberta, o que gerou uma grande variedade de respostas. Comentamos, aqui, as mais assinaladas em cada categoria.

Destacamos, inicialmente, a baixa incidência de referências a mulheres envolvidas na composição das obras. Somente Zíbia Gasparetto, Joana de Angelis e Yvonne Pereira foram citadas; embora Patrícia não tenha sido citada, seu romance Violetas na janela (1993) teve muitas menções. ${ }^{15} \mathrm{O}$ título, nesse caso, supera em fama a sua autora.

\footnotetext{
${ }^{14}$ Os leitores não frisaram a importância das editoras na escolha dos livros espíritas; sabemos, contudo, que a editora da Federação Espírita Brasileira (FEB) atua também no imaginário coletivo dos espíritas como instrumento de chancela de livros espíritas "confiáveis", ou, melhor dizendo, de livros coerentes com a Doutrina dos Espíritos. Isso ocorre porque seus livros passam por rigorosa análise doutrinária, como fica explícito nas políticas editoriais de avaliação de originais, que priorizam "a fidelidade doutrinária, a contribuição para a formação moral e intelectual das pessoas; os valores e atitudes veiculados no texto; o ineditismo de conteúdo ou abordagem inovadora sobre conteúdo conhecido; a adequação ao perfil do leitor; o ajustamento das abordagens usadas pelo autor; as referências e fontes utilizadas; a legibilidade textual" (FEB, s.d.). Metade dos critérios tem ligação com o rigor doutrinário e com o objetivo da editora (divulgação do espiritismo pela formação de leitores), os demais estão ligados à legibilidade da obra e adequação ao público.

${ }^{15}$ Os leitores não parecem distinguir as diferentes funções na composiç̃o da literatura espírita; frequentemente atribuem a autoria, nas obras psicografadas, não ao espírito que as dita (como Joanna de Ẩngelis, mencionada), mas ao médium psicógrafo (como é o caso de Yvonne Pereira e Zíbia Gasparetto).
} 
Sublinhamos também que a maioria dos livros mencionados foram psicografados pelo médium mineiro Francisco Cândido Xavier (1910-2002), que aparece como o autor mais admirado, muito embora não tenha ele atribuído a si mesmo a autoria de nenhuma das mais de 400 obras por ele psicografadas. A onipresença de Chico Xavier na pesquisa se deve ao fato de o médium ter sido um dos maiores divulgadores do espiritismo no Brasil, além de gozar até hoje de grande influência no meio espírita.

Dentre as obras relatadas como leituras literárias em curso no momento da pesquisa figuram os romances Paulo e Estevão (Emmanuel, 2012) com 419 votos; seguido de A caminho da luz (Emmanuel, 2013), com 316 votos. Em terceiro lugar temos Os mensageiros (André Luiz, 2017), com 249 menções. O conhecido romance Nosso lar (André Luiz, 2012) figurou em quarto lugar no ranking das respostas, com 219 votos, seguido de Boa nova (Humberto de Campos, 2017), com 158 indicações. Libertação (André Luiz, 2013) ocupa o sexto lugar (133 votos) e No mundo maior (André Luiz, 2013) ficou em sétimo, com 130 indicações. Na sequência, temos Sexo e destino (André Luiz, 2013) e Obreiros da vida eterna (André Luiz, 2017), com respectivamente 120 e 118 votos. Os décimos colocados são os romances Há dois mil anos (Emmanuel, 2017) e Francisco de Assis, ${ }^{16}$ com 112 votos cada qual.

As obras básicas da codificação espírita, não literárias, tiveram conjuntamente 2.403 votos, mostrando a preferência pela sua leitura em detrimento da leitura de romances. Isso se deve ao fato de que os espíritas são instados a desenvolverem a leitura da Codificação Espírita durante sua fase de formação, a qual dura entre três e cinco anos, na maioria das casas espíritas. Outras 2.065 pessoas declararam não estar lendo nenhum livro espírita na ocasião.

Boa parte dos romances que estavam sendo lidos na ocasião da coleta de dados foi mencionada como sendo uma obra marcante na vida do leitor, conforme a tabela 8 .

Tabela 8 - Livros marcantes na vida do leitor

\begin{tabular}{l|c}
\hline \multicolumn{1}{c}{ Títulos } & Respostas (No) \\
\hline Obras Básicas da Codificação Espírita & 4.998 \\
Paulo e Estevão (Emmanuel, 2012) & 2.381 \\
Há dois mil anos (Emmanuel, 2017) & 1.138 \\
Nosso Lar (André Luiz, 2012) & 1.821 \\
Violetas na Janela (Patrícia, 1993) & 721 \\
Renúncia (Emmanuel, 2013) & 230 \\
Boa Nova (Campos, 2017) & 320 \\
A Caminho da luz (Emmanuel, 2013) & 316 \\
Memorias de um suicida (Botelho, 2012) & 169 \\
Obreiros da Vida Eterna (André Luiz, 2017) & 163 \\
\hline
\end{tabular}

Fonte: dados da pesquisa.

Confirmado o predomínio da leitura de obras não literárias, as demais, todas romances, pertencem também ao cânone do gênero, ${ }^{17}$ exceto o romance de Patrícia, que gozou de excelente divulgação à época de seu lançamento, constituindo-se logo em best-seller.

Entre os autores mais admirados figuram, como já notamos, tanto os autores de fato (espíritos), como os médiuns psicógrafos, cuja fama "adere" ao título das obras, levando os leitores a confundir as duas funções. Chico Xavier dispara no carinho dos leitores (4.086

\footnotetext{
${ }^{16}$ Francisco de Assis é título de mais de um romance, de modo que não temos como determinar a qual deles os leitores estão se referindo na pesquisa.

${ }^{17}$ Consideramos canônicas, na literatura espírita, as obras de alguns espíritos que se destacam como inquestionáveis, tais como Emmanuel, André Luiz, Joanna de Ângelis e outros.
} 
votos), ocupando um primeiro lugar que em muito se distancia do segundo, que é ninguém menos que o seu mentor espiritual, Emmanuel (2.207 menções). O médium baiano Divaldo Franco, também popular no meio espírita, vem em terceiro lugar, com 1.334 votos, seguido do autor extrafísico André Luiz, com 532 indicações. O codificador Allan Kardec vem em quinto lugar na preferência dos leitores, tendo angariado 495 votos. Em seguida, em ordem decrescente, temos Zíbia Gasparetto (480 votos); Joanna de Ângelis (Espírito), mencionada 375 vezes; o pesquisador francês Leon Denis (328 votos) e o médium Manoel Philomeno de Miranda (288 votos), seguido de Yvonne Pereira, que fecha nossa lista com 283 votos. Destacamos a predominância de nomes masculinos na memória afetiva dos leitores.

\section{Considerações finais}

O intuito da pesquisa realizada foi verificar o perfil do leitor de livros espíritas. Para isso, 15.619 pessoas foram ouvidas, em todo o território nacional. A coleta de dados foi feita por meio de questionário disponibilizado digitalmente, o que facilitou sua veiculação.

Os dados obtidos na pesquisa nos permitem traçar o perfil atual da leitora média de livros espíritas: ela é do gênero feminino, tem cerca de 50 anos, nível superior e renda entre cinco e dez mil reais; gosta de comprar livros que depois da leitura ornam suas estantes particulares. Essa leitora lê principalmente para obter conhecimentos, é estudiosa e praticante da Doutrina dos Espíritos, o que lhe traz também consolação e conforto.

Seus autores prediletos são a dupla imbatível Chico Xavier e Emmanuel, sendo deles os romances mais marcantes: Paulo e Estêvão e Há dois mil anos. Os enredos das duas obras se passam na época de Jesus, ou nos primeiros anos depois de sua desencarnação, de onde supomos que, pela leitura, a leitora espírita média ocupa lugar de espectadora imaginária do cristianismo nascente; isso provavelmente vai ao encontro de seu desejo íntimo de comunhão com Jesus, a quem tem por mestre e amigo.

Embora as leitoras sejam em número muito superior aos leitores, temos mais autores e médiuns do sexo masculino que autoras e médiuns femininas. Nisso não difere este quadro daquele da literatura tradicional, em que a incidência de autoria feminina fica ainda muito aquém, em números, da masculina. A escrita da literatura espírita ainda é, pois, território a ser conquistado pelas mulheres, como já vem acontecendo com a literatura em geral.

Por fim, a pesquisa permitiu redefinir em nossa imaginação o perfil dessa leitora, que a experiência nos mostrava ser das classes populares. Entendemos, a despeito dos resultados, que com a escolarização crescente das camadas menos favorecidas da sociedade brasileira, também os romances espíritas têm potencial para atingir novos públicos, esparramando assim mais rapidamente a sua mensagem consoladora.

\section{Referências}

ADRIA, Kesi (2016). Mercado de livros espíritas cresce 85\% em uma década. O Liberal, Campinas, 19 ago. 2016. Disponível em: https://bit.ly/2YBuJ9w. Acesso em: 20 jun. 2018.

AMORIM, Galeano (2008). Retratos da leitura no Brasil. São Paulo: Imprensa Oficial.

CAVALCANTI, Maira Laura Viveiros de Castro (1983). O mundo invisível: cosmologia, sistema ritual e noção de pessoa no Espiritismo. Rio de Janeiro: Zahar. Disponível em: https://bit.ly/2WNWIYp. Acesso em: 15 abr. 2018.

CAMPOS, Humberto de [Espírito]. Brasil, coração do mundo, pátria do evangelho. Psicografia de Francisco Cândido Xavier. 34. ed. Brasília: FEB, 2015.

DARWIN, Charles (2017). Origem das espécies. Tradução de Joaquim da Mesquita Paul. [s.1.] Textos para Reflexão. E-book Kindle. 
DIAS, Haroldo Dutra (2018). Sexualidade e gênero - Espiritismo. Palestra. (7m24s). Disponível em: https://www.youtube.com/watch?v=gxMP2HhAIzg. Acesso em: $1^{\circ}$ maio 2019.

ESPIRITISMO - números materializados (2012). Superinteressante, 28 maio 2012. Disponível em: https:/ / bit.ly/2w4qvea. Acesso em: 9 abr. 2018.

FEB - FEDERAÇÃO ESPÍRITA BRASILEIRA (s.d.). Perguntas frequentes. On-line. Disponível em: http://www.febeditora.com.br/perguntas/

FRANZOLIM, Ivan (2012). Quantos somos? Dados do censo revelam o crescimento do número de espíritas e a diferença entre outros grupos religiosos. São Paulo: Vinha de Luz, 13 ago. On-line. Disponível em: https:/ / bit.ly/2JL4fOv. Acesso em: 20 jun. 2018.

GARCIA, Wilson (2015). Nossas editoras entraram num caminho comum. E agora? In: GARCIA, Wilson. Expediente-on-line: blog do Garcia. Disponível em: https://bit.ly/2HAoawH. Acesso em: $1^{\circ}$ mai. 2019.

KARDEC, Allan (1984). O livro dos médiuns. Tradução de J. Herculano Pires. São Paulo: FEESP.

KARDEC, Allan (2000). O livro dos espíritos. Tradução de Sandra R. Keppler. São Paulo: Mundo Maior.

KARDEC, Allan (2004). Frenologia espiritualista e espírita: perfectibilidade da raça negra. Tradução de Evandro Noleto Bezerra. Revista Espírita: jornal de estudos psicológicos. Brasília: Federação Espírita Brasileira. p. 141-152.

LEWGOY, Bernardo (2000). Os espíritas e as letras: um estudo antropológico sobre cultura escrita e oralidade do espiritismo kardecista. Tese (Doutorado em Antropologia Social) - Faculdade de Filosofia, Letras e Ciências Humanas, Universidade de São Paulo, São Paulo.

MANSUR, Alexandre; CORDEIRO, Tiago (2003). Sucesso do outro mundo. Época, Rio de Janeiro. On-line. Disponível em: https://glo.bo/2QaU86W. Acesso em: 15 maio 2018.

MUNANGA, Kabengele (2003). Uma abordagem conceitual das noções de raça, racismo, identidade e etnia. In: SEMINÁRIO NACIONAL RELAÇÕES RACIAIS E EDUCAÇÃO, 3., 5 nov., PENESB-RJ, Niterói. Palestra. On-line. Disponível em: https:// bit.ly/2tdEOMY. Acesso em: 28 jun. 2018.

NAKAGOME, Patrícia Trindade (2017). Os caminhos da leitura: a reta e o círculo. In: PEREIRA, Danglei de Castro. Nas linhas de Ariadne: literatura e ensino em debate. Campinas: Pontes. p. 131-141.

PODE SER GAY? (2017). Direção e Produção: Fábio Olivieri. Roteiro: Fábio De Lucca. Intérpretes: Alex Moczydlower; Fábio de Luca. Rio de Janeiro: Amigos da Luz. Son., Color. 6min35s. Disponível em: https:/ / bit.ly/2o9IPNn. Acesso em: 20 jun. 2018.

SILVA, Ana Claudia da; CARBONARI, Rosemeire (1997). Cópia e leitura oral: estratégias para ensinar? In: CHIAPPINI, Lígia; BRANDÃO, Helena; MICHELETTI, Guaraciaba (Org.). Aprender e ensinar com textos didáticos e paradidáticos. São Paulo: Cortez. p. 95-115.

SOUSA, Hege Laghi de (2013). Darwin e Kardec: um diálogo possível. Campinas: Allan Kardec.

STOLL, Sandra Jackeline (2004). Narrativas biográficas: a construção da identidade espírita no Brasil e sua fragmentação. Estudos avançados, São Paulo, v. 18, n. 52, p. 181-199. Disponível em: https://bit.ly/2EcJYxO. Acesso em: 15 maio 2018. 